\title{
EL PRIMER LORCA Y SU TEATRO INÉDITO DE JUVENTUD
}

\author{
SANTIAGo Trancón \\ I. E. S. Calderón de la Barca (Madrid) \\ strancon@gmail.com
}

\section{RESUMEN}

Se analizan los comienzos artísticos de Lorca sosteniendo la idea de que no hay una clara vocación inicial, sino una sensibilidad artística excepcional abierta a distintas expresiones: música, pintura, teatro, literatura. El impulso vanguardista e innovador surge desde los inicios de su escritura teatral.

Palabras ClaVE: Modernismo; Arte; Vanguardia; Teatro; Originalidad; Vocación.

\section{ABSTRACT}

Lorca's artistic beginnings are analysed emphasizing there isn't a clear initial vocation but an exceptional artistic sensitivity to different expressions: music, painting, theatre, literature. The avant-garde and innovatory impulse appears at the beginning of his theatral wraiting

KEY WORDS: Modernism; Art; Avant-garde; Theatre; Originality; Vocation.

\section{VOCACIÓN MUSICAL Y VOCACIÓN LITERARIA}

Según Andrés Soria Olmedo (1994:11), Federico García Lorca habría empezado escribiendo prosa, luego poesía y por último teatro. Este orden no coincidiría con el de apa- 
rición pública de su obra, que comenzó con Impresiones y paisajes (1918), siguió con El maleficio de la mariposa (1920) y continuó con Libro de poemas (1921). Esta misma opinión parece sostener Francisco García Lorca (1980), quien afirma, además, que Federico se lanzó a escribir con febril agitación al abandonar sus estudios de música en 1916, después de ver frustrados sus deseos de trasladarse a París para proseguir su vocación musical a la muerte de su maestro Antonio Segura.

Según Ian Gibson (1998) Federico empezó a escribir, efectivamente, ya en 1916. Su primera prosa conocida, Mi pueblo, afirma que fue escrita entonces, sin precisar si antes o después de la muerte de su maestro de música.

En 1916 Federico está matriculado en la Facultad de Filosofía y Derecho de Granada. La muerte de su maestro de música ocurre a finales de mayo de este año. Ese mismo verano Federico hace un viaje de estudios por Castilla y Andalucía conociendo, entre otros, a Unamuno y a Antonio Machado. Durante este viaje ya escribe artículos (algunos los publicará en la prensa local) que luego darán lugar a su primer libro, Impresiones y paisajes.

Sobre la base de estos datos, ya parece comúnmente aceptado:

1) Que Federico García Lorca se dedicó a la literatura al no poder continuar su primera vocación musical.

2) Que Federico García Lorca se inició literariamente escribiendo prosa, luego poesía y por último teatro, siguiendo un proceso de depuración artística.

Son estas dos afirmaciones las que, en primer lugar, queremos poner en cuestión. La relación «causal» establecida entre la renuncia de Federico García Lorca a seguir su inicial vocación musical y la entrega a su «nueva» vocación literaria, nos parece algo gratuita y acaso desvirtúe u oculte las inclinaciones e inquietudes que Federico realmente sentía en aquellos sus inicios artísticos. Creo que se exagera su vocación musical y la influencia que tuvo el fallecimiento de su maestro Antonio Segura para que «abandonara» esta vocación. Si Federico realmente hubiera querido proseguir sus estudios musicales y dedicarse exclusivamente a ello, yo creo que lo hubiera hecho, al margen de las circunstancias adversas que se le presentaron inesperadamente. Así lo demostró al seguir su vocación literaria, tan llena de dificultades como lo hubiera sido el continuar sus estudios o su dedicación a la música. Federico era muy obstinado en todo lo que se refería a sus proyectos artísticos, a los que siempre se entregaba con ilusión, constancia y una fe firme en sus capacidades.

Tampoco sabemos, por otra parte, qué hubiera ocurrido en caso de que su maestro no hubiera fallecido. Es pura conjetura el suponer que entonces no se hubiera dedicado a la literatura, o que se hubiera dedicado sobre todo a la música, tal como parece dar a entender lo determinante de este hecho. Más bien creemos que su vocación musical, indiscutible, no era ni mucho menos aquello a lo único a lo que aspiraba a dedicarse $\mathrm{Fe}-$ derico. Como tampoco lo era su vocación literaria en aquellos momentos. Sin duda la muerte de su maestro fue una contrariedad importante que le hizo cambiar la orientación de sus esfuerzos. Pero hay que tener también en cuenta otros factores, como la edad de Federico, la opinión de sus padres y lo que podían ser los usos más frecuentes entre las familias de condición social semejante a la suya. Lo más sencillo es pensar que ni sus pa- 
dres deseaban que Federico se dedicara a la música como profesión, ni que socialmente se esperara eso de él ni de ningún joven de su edad y condición. Como tampoco lo era el que se dedicara a escribir poesía o teatro. Lo normal era que ni él y sus padres pensaran entonces que la música fuera una vocación exclusiva a la que se podía dedicar profesionalmente. Simplemente se preocuparían de que continuara sus estudios, como así ocurrió, y de que ni la música, ni cualquier otra «vocación» o «afición» le impidiera el proseguirlos.

Esa idea de dos vocaciones absorbentes y mutuamente incompatibles, que nos colocan al joven Federico ante una decisión fundamental de la que nada menos iba a depender su futuro literario, nos parece una fantasía. Yo creo, además, que ni Federico «abandonó» la música por la literatura (de hecho siguió desarrollando sus dotes musicales e interesadísimo por la música que de verdad le atraía, la música popular y la de los compositores de vanguardia del momento -Falla, Debussy, etc.-), ni, lo que igualmente nos parece aventurado, la vocación literaria de Lorca nació de esa renuncia a su vocación musical o como consecuencia de ello. Aún en el caso de que cronológicamente coincidieran esos dos hechos - el «abandono» de la música y su dedicación «exclusiva» a la literatura- podríamos hacer tal afirmación. La «coincidencia» cronológica puede incluso ser discutible.

¿Cuándo empezó Lorca a interesarse por la literatura y por la escritura? No parece verosímil un súbito descubrimiento de la literatura y de su vocación literaria. Rubén Darío y Juan Ramón Jiménez, Unamuno y Machado, Valle-Inclán y Ganivet, Zorrilla y Víctor Hugo, por ejemplo, debieron ser lecturas asiduas desde muy temprano. ¿No sabemos que disfrutaba y se apasionaba por el teatro desde muy niño? ¿No nos dice que su madre le leía a Víctor Hugo desde pequeñito? Su vocación literaria crece con él desde su infancia, lo mismo que su afición musical. Parece mucho más aceptable suponer que la vocación literaria de Lorca no fue algo repentino, sino que, como todo en su personalidad creativa, hunde sus raíces en gustos, experiencias y tendencias muy tempranas. Otra cosa es que, formalmente, esta vocación aflore o se manifieste en un momento determinado, como bien pueden ser estos años de 1916 y 1917. Pero existe un «magma» común del que nace su afición por la música y su interés por la literatura. Su familia, su entorno, el flamenco, la canción popular, los romances, las historias contadas por criadas y criados, las lecturas en público de su madre, las ceremonias religiosas, el teatro de títeres, el teatro modernista y realista de la época... Su sensibilidad, su capacidad de observación y percepción, su memoria extraordinaria..., todo esto le impulsaba a una experiencia del arte y la literatura muy intensa y particular, algo que tenía que ver con una actitud artística y vital, en la que no podemos hacer distinciones excluyentes entre música popular y vanguardista, canciones populares y poesía, teatro de títeres y romances, observación de la naturaleza y gusto por el dibujo y la pintura, etc. No tiene mucho sentido establecer jerarquías artísticas si nos acercamos a la capacidad creativa y la actitud vital de Federico desde dentro. Hemos de referirnos a una concepción artística global, a su idea de la belleza, del drama, de la música, la poesía, el arte y el artista. Esta concepción le facilitó a Federico la asimilación de todo lo nuevo que empezaba a surgir en el arte y la literatura y su acercamiento a los postulados vanguardistas que más tarde van a dar lugar a movimientos concretos. Ya en su primer libro Impresiones y paisajes (1998: tomo IV, 51), encontramos afirmaciones de este tipo: 
La poesía existe en todas las cosas, en lo feo, en lo hermoso, en lo repugnante [...] Lo admirable de un espíritu está en recibir una emoción e interpretarla de muchas maneras, todas distintas y contrarias [...] Es imprescindible ser uno y ser mil para sentir las cosas en todos sus matices.

Entender la vocación artística de Lorca de este modo, unida a su visión del arte en general, por encima de inclinaciones concretas, tiene ventajas a la hora de interpretar sus primeros escritos. Al desvincular la dedicación e interés por la literatura de su frustración musical nos permite estudiar mejor los orígenes de la escritura lorquiana o rastrear influencias tempranas. Uno de los aspectos básicos de la primera escritura lorquiana es la estrecha relación que guarda con la música, no sólo en lo que se refiere al ritmo y el sentido musical de la palabra y la sintaxis, sino también por la influencia directa de las estructuras musicales sobre la estructura formal de muchos de sus textos. Habría que estudiar la relación de sus tragedias y comedias con la ópera, por ejemplo («ópera romántica» llamó Gerardo Diego a Mariana Pineda); o las relaciones entre romance y flamenco, sus canciones y poemas, con la música popular, etc. Muchas veces las estructuras musicales se toman como base de las estructuras textuales. Algunos de sus poemas inéditos de juventud los titula «Balada», «Sinfonía», «Ritornelo (en clave de fa)», «Aria de primavera», «Acordes mayores», «Música de circo». En su prosa de juventud encontramos títulos como «A modo de antífona irónica», «Como un ritornello angustiado», «Trémolo de timbal», «Sinfonía mágica», «Primer tiempo: largo misterioso y luminoso», «Segundo tiempo: el caos, lo infinito», «Nocturno apasionado. Lento», «La sonata de la nostalgia», «Primer tiempo: molto allegro appasionato», «Andante: nolto allegro disparato», «Adagio cantabile», «Allegro con furia», «Molto allegro con fuoco», «Allegro ma non tanto y desfallecido», «Balada en fa sostenido mayor», etc.

También nos ayuda a «interpretar» el posible vanguardismo de los primeros textos lorquianos el ponerlos en relación con la música y con la concepción que de la música tenía entonces el joven Lorca. El uno de sus primero escritos publicados, Divagación. Las reglas de la música (1998: tomo IV, 42-44), nos muestra claramente su concepto moderno y vanguardista de la música: «La música es en sí apasionamiento y vaguedad [...] Con la música se expresa eso que nadie conoce ni lo puede definir [...] Para sentirla es necesario poseer imaginación loca y nerviosa». Nos habla de «las modulaciones maravillosamente desquiciadas de Debussy», y de que las reglas en la música sólo son necesarias para la iniciación, luego son inútiles. Defiende las «alteraciones inarmónicas o armonías raras» con un argumento muy revelador: «¿Qué cosa más desquiciada que el dolor?»

Pero lo curioso es que estas mismas ideas las traslada a la literatura y así alaba a Rubén Darío, al que llama «El Magnífico», porque «rompió todas las reglas, pero con aquella cantidad de ideas y de espíritu que guardaba su corazón». Y acaba: «Las reglas se han hecho tan sólo para las mediocridades».

Lorca ve en el carácter inaprehensible de la música y su lenguaje inefable, un elemento esencial que tratará de llevar a la poesía. Música y literatura comparten un fondo y una esencia que en ningún momento las hace incompatibles ${ }^{1}$. Podríamos decir que Lor-

\footnotetext{
${ }^{1}$ Otro tanto podríamos decir de la pintura. Lorca sintió la misma atracción por el dibujo y la pintura, por eso también se dedicó a ella. Recordemos que llegó a hacer una exposición de sus dibujos y pinturas en Barcelona.
} 
ca se adentra en el arte tanto a través de la música como de la pintura y la literatura, y que en su primera aproximación se siente atraído por lo nuevo, lo que no respeta las reglas, lo que resulta inexplicable, una actitud prevanguardista cercana a lo que luego la vanguardia iba a explorar intensamente. Seguramente la literatura fue el molde más adecuado para que Lorca volcara en ella toda su creatividad. La música y la pintura se integrarían en la literatura de forma natural, de ahí que toda su obra está tan llena de «música y color», de descripciones musicales y plásticas, de estructuras rítmicas, sonoras y pictóricas. Su sensibilidad musical y plástica, trasladada a la escritura, le llevaría a la búsqueda de expresiones que muy pronto rebasarían los límites del modernismo y el neorromanticismo en el que se había educado.

\section{JERARQUÍA DE GÉNEROS Y PROCESO DE ESCRITURA}

Tampoco nos parece de especial interés el establecer una jerarquía (en su proceso de aprendizaje o dedicación literaria) entre la diversidad de géneros que cultivó durante toda su vida: teatro, poesía y prosa (reflexiones, artículos, ensayos y conferencias). ¿Fue primero la prosa, luego la poesía y por fin el teatro? ¿Se pude interpretar esto como un proceso que va de lo subjetivo a la objetivación? No nos parece que haya argumentos a favor de esta interpretación, un tanto contradictoria. Soria Olmedo, siguiendo a Francisco García Lorca (también García Posada opina así), nos habla de un proceso de «depuración artística» que va de «la descripción de sus propias emociones» hacia la «objetivación» teatral. Pero sería más lógico afirmar, si así fuera, que Lorca comenzara por escribir poesía (lo más subjetivo) y no prosa, pues es en la poesía donde mayor cabida tienen las emociones del joven adolescente que entonces era.

No tenemos datos para hacer afirmaciones tan forzadas, entre otras cosas porque carecemos de una cronología fiable de sus escritos juveniles inéditos. Más bien parece -lo que, por otra parte resulta más verosímil-que la ebullición literaria le lleva a Lorca a buscar desde sus comienzos todas las vías de expresión y creación posibles.

No habría, según mi opinión, un proceso que va, primero, de la música a la literatura, y luego, de la prosa subjetiva a la objetivación teatral. Me parece demasiado «lógico» y lineal este proceso, fruto de una interpretación, más que de la comprobación de unos hechos. También parece aventurado el suponer que la insatisfacción de un género literario fuera lo que forzara o impulsara a Federico a pasar a otro, como buscando formas más adecuadas y depuradas. Más bien parece que nos encontramos ante un desarrollo y experimentación paralelos, con influencias mutuas, entre prosa, poesía y teatro, sin que se abandone una cosa por la otra, un género por otro. Lo que observamos es que Lorca empieza a escribir prosa lírica y de temas personales, artículos de denuncia y ensayos «metafísicos», por un lado, y poesía y teatro, por otro, pero prácticamente todo al mismo tiempo. Las diferencias cronológicas - de muy difícil comprobación- en la aparición de sus escritos, no nos dan suficientes argumentos como para deducir la existencia de un proceso -y mucho menos conscientecon una clara dirección hacia la depuración y la objetivación. Las correspondencias intra e intertextuales de los escritos de estos primeros años nos indican que esto no ocurrió así.

Encontramos más bien un intento de superar los límites de los géneros, y así aparece poesía en medio de la prosa (prosa muchas veces poética), pero también diálogos te- 
atrales. En sus primeras piezas dramáticas hay abundante poesía, algunas están en verso y otras, aún escritas en prosa, las denomina «poema trágico», «poema dramático», etc. Algunos poemas, a su vez, tienen estructura dramática y dialogal.

Su primer texto publicado, Fantasía simbólica, acaba con la frase «Granada era un sueño de sonidos y colores» (1998: tomo IV, 41) y, aunque está escrito en prosa, la mitad del mismo tiene estructura dramática con los siguientes personajes dialogando: La campana de la Vela, La voz, El Darro, La voz de Ganivet (con sonido de rosa marchita), El río (muy fuerte), La ciudad (con voz de campana).

Los textos en prosa de sus primeros escritos titulados «Balada apasionada y dolorosa», «Balada», «El poema de la carne. Nostalgia olorosa y ensoñadora», «El poema del caminante», «Canción simbólica», «Un vals de Chopin», «Coros de faunos», «Sonata que es una fantasía», «Balada en fa sostenida mayor», están estructurados en forma de diálogos teatrales, en donde hablan personajes como «el hombre joven», «la voz del viejo», «Rubén Darío», «Don Quijote», «Safo», «Platón», «Coro de griegos», «Coro de romanos», «La música», «La nieve», «El caminante», «El monte», «El sol», «El piano», «Él», «Ella», «Coro de sirenas», «Los faunos», «El cuerpo», «El espíritu», «Los violines», «Las trompas», «Los maizales», «Los grillos», «Los molinos (a lo lejos)», «Las piedras, «, «El musgo», «Las ranas», «El agua (con alta voz de cascada)»... Estos textos pueden considerarse tanto prosa como diálogos teatrales. La simple enunciación de títulos y personajes nos habla de un Lorca con gran imaginación y deseos de búsqueda y experimentación, una actitud que podemos considerar «vanguardista».

También nos interesa el poner en duda ese proceso lineal y afirmar, por el contrario, mutuas correspondencias e influencias entre los géneros desde los inicios de su dedicación literaria, porque este hecho explica mucho mejor la evolución y originalidad de estas piezas teatrales y en general de sus primeros textos. Sería esta necesidad de desbordar o de no limitarse a las convenciones de género, la que daría a Lorca una mayor libertad para experimentar con formas y fórmulas nuevas en busca de su propia voz. Es la no limitación a los géneros lo que permite a estos textos teatrales ir más allá del gusto modernista y adentrarse en terrenos cercanos a la vanguardia. Ya hemos visto que en su prosa juvenil hay diálogos teatrales que muy bien pudieran incluirse en una selección teatral. En algunas piezas de su teatro inédito, a su vez, hay acotaciones que son más prosa que texto dramático. El impulso poético, por otra parte, invade o envuelve a estos textos desde sus comienzos.

Otro aspecto que conviene poner en duda es el de la «subjetividad» de los primeros escritos de Lorca, en oposición a la mayor objetivación de su escritura posterior. En realidad nos llama la atención lo contrario, el hecho de que los primeros escritos de Lorca, independientemente de su calidad, no son propiamente «literatura adolescente», o sea, que no son tan subjetivos como lo suele ser esa primera literatura de un joven escritor al que se le supone con graves problemas de identidad sexual y de adaptación a una sociedad tan machista como la que rodeaba a Lorca en su adolescencia. Lorca parece consciente desde sus inicios de que lo personal no puede ser objeto directo de la escritura literaria, y por eso no adopta en ningún momento un tono confesional, intimista o sentimental. Lo que hay de subjetivismo y sentimentalismo en sus primeros escritos se debe más a la moda modernista y neorromántica del momento, que a sus propios problemas interiores. El tono reflexivo y distanciado nos sorprende muchas veces. Su prosa 
y su poesía (al igual que su teatro) tienden a lo impersonal, lo simbólico, lo metafísico, lo existencial, y por eso se dramatizan o adoptan estructuras dramáticas o teatrales con frecuencia. Su romanticismo, por otro lado, se atenúa con reflexiones metafísicas y preocupaciones religiosas y sociales expuestas de modo bastante abstracto y poético, más que lírico o subjetivo. Es cierto que esta escritura está contaminada de la emocionalidad propia de su edad, pero no se queda encerrada en estos límites. Nos encontramos a veces con frases, versos, diálogos que resultaría difícil diferenciar de otros encontrados en los textos de su obra madura.

\section{TEATRO INÉDito DE JUVENTUd}

\subsection{Comedieta ideal (1917). ¿Inicios vanguardistas?}

El primer texto teatral, cronológicamente hablando, es esta pieza titulada Comedieta ideal. Esta obra nos plantea gran cantidad de preguntas de muy difícil respuesta, como nos ocurrirá con el resto de textos que vamos a analizar brevemente.

La Comedieta ideal es un texto que refleja originalidad y experimentación propias, no deudoras de otros géneros en los que el poeta no pudiera expresar sus emociones, ideas e inquietudes. La estructura formal es teatral, pero no responde a una idea de «representación», no hay propiamente un intento de proyección sobre la escena de este texto (sí lo habrá en los textos posteriores, sobre todo a partir de La viudita que se quería casar, de 1919). Es, en sentido estricto, «teatro literario». No sabemos en qué ni en qué autores se puedo inspirar. La influencia literaria del modernismo y el simbolismo, con su gusto por la metáfora y la sinestesia, parece clara. Otra referencia puede ser el teatro poético del momento (Marquina, Villaespesa, etc.), pero tampoco podemos rastrear una influencia directa de este tipo de teatro que, sin duda, Lorca ya conocía bastante bien por estas fechas. No tenemos más remedio que hablar de originalidad.

Junto a la originalidad también nos podemos aventurar a hablar de «vanguardismo» o de la existencia en estos textos de elementos o rasgos vanguardistas más o menos definidos. Resulta muy difícil y aventurado el determinar claramente el origen de esta presencia vanguardista. ¿Conocía en estos momentos Lorca algo de los primeros vanguardismos, el dadaísmo y el futurismo, por ejemplo? No podía tener más que vagas referencias, si es que las tuvo, de movimientos que en España no empezarían a tomar cuerpo o presencia más que a partir de 1918.

Más bien nos inclinamos a pensar que Lorca actúa de forma intuitiva, dejándose llevar por su imaginación e interpretando de modo muy personal lo que podían ser pequeños síntomas o signos de una nueva época, nuevos gustos e inquietudes. El impulso básico, más que de influencias externas o directas, surgiría de su personalidad creativa y la necesidad de experimentar y buscar su propia voz.

Hay otra explicación que, si bien tiene un fundamento puramente especulativo o metafísico, no deja de resultar intelectualmente elegante. Me refiero a lo que se ha llamado «el espíritu de una época», el hegeliano «espíritu de los tiempos» (zeitgeist): esa confluencia de factores históricos que configuran la mentalidad de un momento, un ambiente, unos gustos, una sensibilidad, la orientación hacia determinadas formas, ideas y 
temas que caracterizan a los hombres o artistas de un determinado momento histórico. García Lorca, dotado de gran sensibilidad e inquietudes, habría sabido conectar muy temprano con el «espíritu vanguardista» que empezaba a invadir todo el arte europeo del momento $^{2}$, algo que algunos hombres, movidos por cierto impulso «impersonal», iban a tratar de dar forma a través de movimientos concretos, convirtiéndose en líderes o defensores de cambios estéticos y artísticos radicales. El que fueran unos u otros quienes lideraran esos cambios sería algo secundario, como el nombre o la efímera duración de los movimientos que generaron. «La vanguardia» sería algo más que los movimientos vanguardistas de esta época, respondería a una sensibilidad y a una necesidad del arte en general, fruto de las transformaciones sociales, políticas, científicas y técnicas del momento.

Por todo esto nos parece interesante analizar y conocer mejor estos primeros textos teatrales inéditos, muchos de ellos incompletos, confirmando así su carácter de búsqueda o experimentación. Lorca es dramaturgo, digamos, desde el primer momento, lo mismo que poeta. Estos textos así lo confirman. Lorca también es «vanguardista» desde sus inicios, al margen de que nunca se sintiera integrado en ningún movimiento vanguardista concreto (recordemos los intentos frustrados de Guillermo de Torre para que se adscribiera al ultraísmo).

Para mejor interpretar lo que decimos sería necesario precisar el sentido del término «vanguardista» y sus posibles acepciones. Dado el uso tan extendido y abusivo del término, deberíamos distinguir entre:

— «Vanguardia» y «vanguardista» como términos genéricos de amplio sentido, sinónimos de «ruptura»e «innovación».

— «Actitud vanguardista» como algo distinto de la «militancia» o adscripción a un movimiento concreto.

- «Movimiento vanguardista» concreto u organizado, que aspira a intervenir como tal en la vida artística, cultural o social del momento (las llamadas «vanguardias históricas» de entreguerras).

— «Creación vanguardista» como obra artística concreta, literaria, pictórica, musical, etc., con características formales y temáticas que, si bien pueden encontrarse en otros textos u obras no estrictamente vanguardistas, en estas creaciones adquieren un lugar central, tanto por la extensión como por la intención de sus autores.

— «Vanguardia literaria»y «vanguardia teatral». La vanguardia teatral busca una ruptura con el teatro realista y la comedia burguesa, y no afecta sólo al texto, sino a todos los elementos de la representación (espacio escénico, interpretación, música, iluminación, etc.)

Federico García Lorca es vanguardista en sentido amplio, su actitud vanguardista se manifiesta desde sus inicios literarios y tiene creaciones propiamente vanguardistas. No puede relacionársele directamente, sin embargo, con ningún movimiento vanguar-

\footnotetext{
${ }^{2}$ A ello contribuiría el ambiente de libertad e inconformismo que se vivía en la tertulia del café El Álamo de Granada, ese grupo de jóvenes excéntricos, inquietos y brillantes que se reunían en «El Rinconcillo».
} 
dista, ni siquiera con el surrealismo, del que estuvo más cerca, pero al que nunca perteneció realmente. Porque en Lorca hay muchos elementos, al mismo tiempo, que lo alejan de la vanguardia y de las vanguardias históricas, y aquí radica la dificultad de distinguir o diferencias la presencia de elementos o rasgos vanguardistas puros en la obra de Lorca. No conviene forzar la interpretación y hacer decir y hacer a Lorca lo que nunca quiso hacer ni decir. Debemos estudiarlo en su complejidad, esa complejidad que encierran todos sus textos en los que, después de una primera aproximación en que nos deslumbran, descubrimos mundos que nos inquietan y hacen imposible cualquier reduccionismo simplificador, como encuadrarlo en un movimiento literario concreto. Su obra tiene un carácter fuertemente personal y original, que desborda las características o rasgos que definen cualquier tendencia o movimiento literario y artístico de su época.

García Lorca ocupa también un lugar destacado e indiscutible dentro de lo que hemos llamado la «vanguardia teatral», por su afán e interés en modificar los gustos y las convenciones del teatro burgués dominante. Esta faceta de Lorca está muy estudiada y reconocida, y no es objeto del presente trabajo, que se limita a indagar posibles elementos o rasgos vanguardistas de carácter literario en sus primeros textos teatrales

Tanto en las acotaciones escénicas como en el diálogo de esta breve pieza, nos encontramos con imágenes insólitas y construcciones metafóricas que sobrepasan el modernismo. No podemos afirmar que tengan un origen vanguardista, ni siquiera una voluntad de ruptura, pero creemos que ya no pueden encerrarse en los cánones o gustos de la estética modernista y neorromántica. Muchos de estos elementos parecen surgir directamente de la imaginación libre del autor, de asociaciones no lógicas, y si bien tienen una justificación poética, no son siempre fácilmente interpretables. Veamos los más llamativos.

Acotaciones escénicas del Cuadro I:

«El suelo es de amapolas, margaritas, malvarrosas, anémonas y jacintos, mezclados con hongos rosa y rojos y negros, y yedras umbrosas...». Vemos aquí una acumulación de sustantivos y adjetivos y el uso del polisíndeton que, si bien remite a un escenario modernista, lo abigarrado de la descripción parece responder ya a un gusto estético distinto.

«Entre las sombras del suelo hay conchas gigantescas mostrando el iris de su nácar e instrumentos de música severamente colocados...». Nos llama la atención, dentro del léxico modernista, la asociación de elementos naturales (conchas marinas) con instrumentos musicales «severamente colocados».

«Una concha se abre y aparece sobre su iris un hombrecillo vestido de seda amarilla con cuernos dorados y manos de cristal... Sale de la concha y comienza a declamar». La imagen es teatralmente llamativa y responde también a esa necesidad de asociaciones fantásticas o ilógicas, llenas de contrastes cromáticos (un hombrecillo con «cuernos dorados» $\mathrm{y}$ «manos de cristal»).

«El hombrecillo de sedas y cristales maravillosos salió de la concha y traspasando la columnata cayó en la luz crepuscular convertido en chorro de topacios, amatistas, diamantes y mil piedras preciosas...Y la figura divina de Anís al pasar la columnata se hizo incienso, olor y llamaradas azules que desaparecieron entre el trémolo gigante de la luz. Las conchas quedan vacías y la escena desierta. Los violines lejanos suenan más cerca. La luz va huyendo paulatinamente». 
El espacio y las acciones descritas están muy alejadas de cualquier realismo o naturalismo escénico. Su origen modernista y rubeniano parece claro, pero hay cierta exageración y gusto por las transformaciones y cambios mágicos, sorprendentes, fruto de la pura imaginación creadora.

\section{Diálogos del Cuadro I:}

Hombrecillo.-...por una vidriera sonrosada apareció la duquesita niña, vestida de gasas verdes y medio desnuda, que con un violín en la mano lloraba y reía y cantaba y gritaba y se desvanecía moradamente porque había bebido un frasco de licor plateado...

La imagen está descrita mediante la acumulación de verbos y el uso del polisíndeton, a la que se une esa creación adverbial («moradamente») que señala cierto impulso que podemos relacionar con los experimentos verbales de la vanguardia.

Anís.- En los caminos besaré a la hermana muerte. Ahora voy a dejar correr mi sangre por las gargantas de los hombres.

La imagen no es fácil de interpretar. Anís representa las pasiones y emociones ligadas tanto al bien como al mal; es como un impulso vital que está más allá del bien y del mal, lo bello y lo feo. «Voy a causar locuras, placeres, lujurias, amor, llantos, sangre, música...», dice más adelante.

Una voz.- La danza va a comenzar. Los sacerdotes beben en los senos de sus hembras la leche de los niños.

La presencia de Rubén Darío y de los temas eróticos y perversos está presente en el texto, pero hay también cierto «desbordamiento» de los temas y gustos del modernismo decadente.

Acotaciones escénicas del Cuadro II:

En el centro de la isla y sobre rocas gigantescas de acero bruñido está enclavado un fantástico castillo de coral coronado de almenas diamantinas bajo un lúgubre palio de nubes. El agua verdinegra de la inquietud lo cubre a veces borrándolo del infinito. Es la mansión de las almas grandes que tomaron personalidad en la inmensidad. Cerca de él la caverna de los sátiros eternos que buscan inútilmente la carne en el desierto. Por entre las peñas asoman sus cuernos de oro.

Ambiente e imágenes son modernistas, pero llaman la atención esas «rocas gigantescas de acero bruñido» que contrastan con la atmósfera medieval. También es chocante la frase «El agua verdinegra de la inquietud lo cubre a veces borrándolo del infinito», así como esas almas «que tomaron personalidad en la inmensidad».

Esta breve pieza, la primera que conocemos de Lorca, es bastante sorprendente, no tanto por su calidad como por su originalidad y rareza. No sabemos en qué pudo Lorca inspirarse para escribirla. No responde a ningún modelo de teatro de la época. Tampoco parece que fuera escrita pensando realmente en ser representada. Por lo temprano de su escritura (1917), podemos pensar que en Lorca la tendencia a la «objetivación» nace con 
los inicios mismos de su labor literaria. No es algo a lo que llegue después de un proceso previo, como si otras formas de escritura (el ensayo o el poema) no le sirvieran y se viera inclinado a la escritura dramática después de intentar expresarse en otros géneros. No, la forma dramática, la tendencia al uso de la estructura dramática parece que es contemporánea de la experimentación con otros géneros.

\subsection{Breve análisis de las otras obras teatrales}

Vamos a recorrer a continuación el texto del resto de las obras del teatro inédito de juventud de García Lorca, tratando de descubrir algunos elementos que, en sentido amplio, hemos denominado vanguardistas o prevanguardistas. Estas obras son muy variadas, lo que señala el proceso experimental y de búsqueda en que Lorca estaba inmerso. Unas son muy breves, otras más largas; unas están acabadas, otras inconclusas, abandonadas por el autor; unas corregidas, otras tal como surgieron la primera vez; unas en prosa y otras en verso; unas son fantásticas, otras religiosas o metafísicas, otras recrean romances populares. La heterogeneidad de estas obras nos muestra la versatilidad de Lorca, la facilidad que tenía para dramatizar historias, sentimientos o ideas, el conocimiento y uso de estructuras teatrales claras (con personajes, acciones y desarrollo dramático) o la libre experimentación con voces, cuadros plásticos sin apenas acción, o meros diálogos poéticos y de contraste de ideas. El impulso creativo de Lorca rebasa, como ya dijimos, los límites del modernismo, y es aquí donde radica el interés de estas piezas. Veamos algunos ejemplos de cuanto decimos. Seguiremos el orden de escritura de estos textos, si bien no siempre es segura su cronología.

\subsubsection{Teatro de almas (1917)}

Empieza la obra con un recurso metateatral que luego repetirá en su teatro más vanguardista. Un actor se dirige al público. Significativamente comienza diciendo: «Esta comedia, o lo que queráis llamarle»...Más adelante exhorta: «Llenáos de amor, de pasión, de virtud, de vicio. Cuando se ama y se sufre el espíritu toma su ruta enigmática. Nada tiene razón de ser para nuestro pensamiento».

En los inicios de su escritura, Lorca se acerca al irracionalismo, un irracionalismo que nace teñido de misterio o incertidumbre ante los enigmas del hombre y del mundo. No hace bandera de ese irracionalismo, ni lo proclama o exalta en sí mismo, como harán luego los vanguardistas, pero sus inquietudes humanas y literarias le aproximan a la búsqueda de lo irreal que muchas veces aparece a través de lo irracional y lo ilógico. Aunque «podamos saberlo todo, no lo podemos pensar ni expresar», dice más adelante el HOMBRE, personaje casi único de esta pieza. E incluso: «Donde se acaba nuestro pensamiento empieza nuestra alma. Donde se acaba nuestra alma comienza lo desconocido, lo imposible».

En la primera acotación encontramos el uso de la sinestesia simbolista, frecuente en todos los primeros escritos del joven Lorca: «La música de la melancolía hace sonar sus colores...» 
En las acotaciones de la Escena II aparecen algunas frases e imágenes de cariz vanguardista: «Las sombras que llenaban la escena se juntan con ruido metálico». «Bosteza Caronte sobre Venus desnuda».

En la acotación de la Escena III:

Las sombras danzan en tono azul. Aparece por el fondo la bandada majestuosa de los sueños. No tienen forma ni expresión continua. Hay perfiles de mujeres con cuernos de oro. Hay lagartos con ojos de cristal amarillo y túnicas de seda, hay encapuchados raros que se ocultan en su propia vaguedad. Todo girando sin cesar, tomando ya formas monstruosas, ya divinas actitudes de encaje y olor. A veces toman la forma de un corazón. Suena una orquesta aterciopelada y lánguida cuyos temas no se resuelven nunca.

La atmósfera es irreal y fantástica, pero lo destacable es la libertad asociativa y creativa de Lorca, así como esa personificación de los sueños, que luego, hechos personajes, hablarán directamente al HOMBRE. Recordemos la importancia que los sueños adquieren en las vanguardias, especialmente el surrealismo, como símbolo y vía para acceder a esa otra realidad en la que la libertad de asociación entre imágenes y palabras no tiene en cuenta para nada la lógica ni la realidad del mundo cotidiano.

\subsubsection{Dios, el mal y el hombre (1917)}

Esta brevísima pieza presenta algunos ejemplos interesantes de esa experimentación lorquiana inicial, que a veces se acerca al surrealismo. De la primera acotación:

Las estrellas se hunden en todas direcciones y la luz llega desordenada y monstruosa [...] Dios está dormido. A sus pies vigila un monstruo viejo, alado y demoníaco, y sobre sus manos exangües tiene una paloma ciega [...]. En el suelo hay, casi desmoronados por el polvo, una pierna enorme unida a una cabeza, un muñeco roto que tiene la cabeza en el ombligo, etc., etc.

Aquí parece ir más allá de la irreverencia modernista y el gusto por lo demoníaco y perverso. EL LEÓN le dice a DIOS, que se muestra cansado: «Y cómo no, si os habéis tragado cuatro estrellas con gente y todo.

DIOS: Estoy haciendo una mala digestión. ¿Le has dado cuerda al cielo?»

Y Dios acaba roncando mientras «La voz de un pitagórico, a lo lejos», grita: «iLa música de las estrellas!»

\subsubsection{Del amor. Teatro de animales (1919)}

Subtitula a esta pieza «poema dramático». Los personajes son animales, lo que nos remite a El maleficio de la mariposa. Su contenido expresa inquietudes humanas y sociales, preocupaciones muy tempranas de Lorca. Es como una fábula simbólica, en la que los animales encarnan principios, actitudes y valores.

Algunas frases llamativas, son: A Dios le llama el CERDO, «el Gran cerdo que está en los cielos». LA PALOMA replica en otro momento al CERDO: «iQuién no te dice 
que la hormiguita que me sirve de alimento sea una buena madre de familia de las que sacan sus hijitos a tomar el sol y a oír cantar a los ruiseñores?». En una acotación escénica aparece: «El cielo se adormece soñadoramente en su color azul». El azul es un color muy usado por los modernistas, pero la creación adverbial «soñadoramente» parece original. LA PALOMA dice también: «Está el cielo hermosamente azul».

\subsubsection{La viudita que se quería casar (1919)}

Ésta ya es propiamente una obra teatral breve, con su estructura, personajes, acción, conflicto y desarrollo dramático. Escrita significativamente en verso, el argumento está sacado de un romance popular. No hay aquí un tema previo «personal», como pudiéramos ver en las piezas anteriores. La subtitula «poema trágico». En conjunto contiene muy pocos elementos o rasgos que pudiéramos considerar vanguardistas o prevanguardistas. Pero sí algunos significativos.

El uso de la metáfora y la sinestesia aparece en la primera acotación: «Las acacias imprimen en el viento tejidos fantásticos de sus olores blancos». También en la acotación del cuadro I: «Es la cruda noche invernal, apoyada con garras de tinieblas en los encinares lejanos».

EL MARQUÉS, en la escena III del Acto I, refiriéndose a la campana, usa unas metáforas muy «lorquianas» y vanguardistas:

Vuelca tu negra copa,

Llena de risas claras.

La campana es una copa negra que, en un fuerte contraste, vuelca «risas claras» (otra sinestesia):

Como una flor de bronce,

Perfuma las cañadas

Desde el tallo de piedra

Donde tus hojas cantan.

La campana es una «flor de bronce» y su sonido «perfuma las cañadas». La torre es «tallo de piedra» y las campas «hojas» que «cantan». Esta acumulación y enlace de metáforas pudiera considerarse una experimentación cercana a la búsqueda de los vanguardistas, si bien mantiene los lazos de la lógica o de la explicación de las metáforas a través de la semejanza y la contigüidad.

\section{¡Mariposa sin alas! \\ ¡Espigas de las nubes! \\ ¡Vida crucificada!}

La primera metáfora se basa en una bella comparación (Mariposa=Campana), pero la segunda resulta ya menos «lógica» o evidente. La tercera, basándose en cierta semejanza $($ Campana $=$ Cruz $)$ supera la comparación y se adentra en un uso metafórico original. 
Lo mismo nos parece la metáfora que usa EL JUGLAR en la escena V del Cuadro II del Acto I. Para referirse a los ojos dice:

Dos abejas cautivas que nunca volarán,

Pero que clavan hondos aguijones de pena.

Y más adelante, señalando a un lindo doncel que está a punto de venir:

Que hundirá en vuestra carne sus azules abejas.

En la acotación de la escena siguiente se lee:

«Queda la escena sola, sintiéndose el sonido de los surtidores y el canto agri-meloso de los árboles».

Añadamos que esta obra está influida por el teatro de Valle-Inclán, tanto en el tema como por el estilo del diálogo y el tono y la sintaxis de las acotaciones.

\subsubsection{Sombras (1920)}

Ésta es una pieza simbólica que habría que relacionar con el teatro simbolista y filosófico de Maeterlinck, del que sabemos que Lorca tenía ya un conocimiento bastante amplio en estos años. Esta influencia bien pudiera estar en el origen de muchos de los experimentos y búsquedas del teatro lorquiano que todavía no ha sido estudiada.

El humor asoma en esta obrita desde el comienzo. Dice la SOMBRA $2^{\underline{a}}$ a la SOMBRA 1ㄹ: «Es que estoy desconcertado, y a ratos, te lo digo con franqueza, me imagino que soy una lechuga! ¡Que tristeza de inmortalidad!». Y más adelante la SOMBRA 3ạ:

¡No he de saberlo! Precisamente he tenido por compañera de viaje al alma de un ministro de esa nación, que, entre paréntesis, canta muy bien las malagueñas y ha referido cómo él se ha transformado sucesivamente en pepino, calabaza, iy en lo que menos se puede figurar usted! ¡en huevo pasado por agua!

El tono, a veces de sainete, nos recuerda por momentos el teatro del absurdo e incluso el famoso Esperando a Godot. Dice la SOMBRA 1ª: «Yo ruego a todas las señoras sombras que tengan paciencia; yo les aseguro que al fin daremos con el reino de Dios».

Replica la SOMBRA VIEJA: «iSi, pero nunca lo encontramos! iy ya hemos recorrido muchas veces el mismo camino!...» (Escena I).

En la escena II dice la SOMBRA DE SÓCRATES:

El mundo es un juguete sin dueño... Yo me he transformado sucesivamente en gato, en rana, en flor, en sombra y volveré otra vez a ser hombre, y así sucesivamente... Y lo más terrible es que se recuerda todo. Es una gran burla que nunca se acaba...

\subsubsection{Jehová(1920)}

Esta obra es la más claramente vanguardista de cuantas hasta ahora hemos comentado. Ya nos encontramos en los años 20. Lorca ha pasado por la Residencia de 
estudiantes y está claro que conoce la existencia y los intentos del dadaísmo, el futurismo y el creacionismo. Aquí no hay duda de que nos encontramos con influencias directas.

Recordemos que en noviembre de 1919 se traslada a Madrid, a la Residencia de Estudiantes, y allí conoce enseguida, entre otros, a Luis Buñuel, Pepín Bello, José Moreno Villa y Emilio Prados, poetas y artistas de grandes dotes e inquietudes artísticas. Por entonces también conoce personalmente a Juan Ramón Jiménez, Manuel de Falla y Gregorio Martínez Sierra, que dirigía el teatro más innovador de Madrid, el Eslava, en el que Lorca estrenaría, con rotundo fracaso, su obra más vanguardista del momento, El maleficio de la mariposa.

Ya en la primera acotación encontramos:

En el centro dos escabeles medievales y un sillón moderno (de una fábrica valenciana). Al fondo un árbol de madera con manzanas de lata. Habrá una serpiente de gasa verde. (Es muy conveniente la instalación eléctrica para producir efectos de apoteosis).

La fascinación por los nuevos inventos y adelantos técnicos está presente en toda la obra, si bien el humor con que todo está tratado hace que debamos relativizar un poco cualquier canto o alabanza del progreso al estilo futurista. El tono general es irreverente y provocador, actitudes ya claramente vanguardistas: «Johová aparece solemne y malhumorado. Le sigue un angelote con la cara despintada y las alas pegadas con sindetikón...». (Debe aludir a la marca de un pegamento «revolucionario» de la época).

Por momentos la obra nos recuerda al Ubú Rey de Alfred Jarry:

JEHOVÁ (Estornudando).- ¡Aaaachísss!

ÁNGEL: ¿Le ha sentado mal la ducha?

JEHOVÁ: Hoy el agua estaba muy fría.

Más adelante reprocha JEHOVÁ al ÁNGEL: «...nunca debieron romper las antiguas costumbres... Tú mismo... ¿Por qué llevas bigotes? ¿Quién te manda llevar peluquín?...» (El peluquín fue un invento muy llamativo de la época).

JEHOVÁ «hace gimnasia» como le ha recomendado LA SERPIENTE. SANTO TOMÁS se ha encargado «un sombrero de copa» y JEHOVÁ replica. «QQué atrevimiento! ¡Eso es hasta antihigiénico!». El ÁNGEL le anuncia más cambios revolucionarios: «Además San Cristóbal boxea y San Jorge juega al tennis». JEHOVÁ añora «los buenos tiempos del Sinaí» y el ÁNGEL le recuerda que «entonces, Señor, los hombres no habían inventado las cerillas». «¡Ay roto misterio del fuego!», exclama DIOS, que también se lamenta de que «con Venus juegan al foot-ball los ángeles atletas».

Luego se habla de «las camisetas de punto», «la telegrafía sin hilos», «la aspirina», etc. El CORO DE HOMBRES le grita a JEHOVÁ: «¡No existes! ¡No existes!». JEHOVÁ llega a decir de su hijo Jesucristo: «Ten mucho cuidado con él: un loco así nos puede dar un disgusto el día menos pensado...»

Los poetas no se salvan del sarcasmo. JEHOVÁ pregunta al ÁNGEL si ha «echado alpiste a los poetas». El ÁNGEL le dice que incluso «lechuga». La obra acaba entonces: Dios se tumba a dormir y de lo único que se lamenta es del ruido de las moscas. 


\subsubsection{Comedia de la carbonerita (1921)}

Esta obra breve, acabada, escenifica y recrea un cuento infantil. Pertenece a lo que podríamos denominar «teatro fantástico y simbolista», escrita bajo la influencia de las nuevas corrientes europeas. Está dividida en seis escenas, con acotaciones teatrales precisas, lo que indica su carácter «representable» y no sólo literario, como ocurre con estas piezas inéditas a partir de Del Amor. Teatro de animales, que ya son obritas con estructura teatral clara y escritas teniendo en cuenta un espacio, un tiempo y un desarrollo plenamente teatrales.

Desde el punto de vista del objeto de este trabajo nos interesa resaltar de esta pieza el tema de los sueños, tan presente en todas las vanguardias, tema que el surrealismo ligó a Freud y el psicoanálisis, pero que ya desde estos años centraba el interés de Lorca por ver en los sueños «la otra realidad», aquella de la que nace la poesía, frente a la realidad de un mundo cada vez más despojado de sueños y de misterio. En el mundo de los sueños, como en el de los cuentos infantiles, todo es posible, como el que una pobre Carbonerita se vaya al bosque a vivir un idilio con su Príncipe.

Dice el leñador ANTÓN, padre de La Carbonerita:

¡Eres tan inocente! Los luceros se caen, y caen marchitos, desilusionados. Los luceros viven con el aceite de nuestros sueños, se mantienen con las miradas de las niñas buenas, con el canto de las niñas buenas, con la cordialidad de los hombres honrados. Pero ha llegado un momento, hijas mías, en que la gente no sueña, y si sueñan no creen en lo soñado. Los hombres creen haber descubierto todos los rincones de la selva y no quieren pisar esos senderos de niebla que llevan al país donde siempre se está con los ojos abiertos. Y naturalmente los luceros se caen, se caen. Yo creo que la noche se va a quedar muy pronto sin espejitos.

Lo que luego será un leiv-motiv de las vanguardias, el rechazo del realismo, el prosaísmo y la falta de imaginación y libertad, aparece aquí sobre un fondo casi existencial: «¿De manera que estamos cercados de sueños?», pregunta el GIGANTE, a quien le molesta que los sueños invadan su casa. Uno de estos sueños personificados, el MANCEBO 2o , gritará: «¡Mueran los sueños intelectuales!». No estamos lejos de las proclamas en defensa del irracionalismo o el rechazo del imperio de la lógica y la razón. Como dice el PRÍNCIPE de forma muy explícita al acabar la obra: «iLos sueños niños han tomado por asalto los campanarios! Mi ejército da un hachazo a la realidad».

\subsubsection{Elenita (1921)}

Ésta es la última obra que Soria Olmedo selecciona en lo que llama «Teatro inédito de juventud» de García Lorca. Está escrita en verso y contiene algunos rasgos que confirman lo que hemos llamado en este trabajo «elementos vanguardistas». Veamos los más importantes.

La obrita, muy corta, está dividida en dos cuadros y en ella aparecen personajes como el BÚHO, el CIPRÉS, DOÑA LUNA, EL CUCO, UNA CASA, UNA RANA, LA FUENTE, UNA LIRIO MADRE, LA ACACIA CON FLOR, EL SAPO, LOS CHOPOS, además de ELENITA, sus padres y un CABALLERO. Lorca sigue todavía con los es- 
quemas de su frustrada obra El Maleficio de la mariposa, que no tardaría en abandonar para dedicarse a lo que fue su segundo estreno teatral, ya muy lejos de estos intentos vanguardistas, Mariana Pineda.

Algunas expresiones literarias de matiz vanguardista aparecen en el texto. Dice UNA CASA:

¡Qué pena de romance!

Ya veis; por mis ventanas

Lloro granos de trigo.

No es fácil saber a qué pueda aludir con estos «granos de oro» (¿Flores?).

LA ACACIA CON FLOR, refiriéndose a los bordados de ELENITA, dice:

Agujas de luna

de tules de agua.

Un leñador viene «de cortar rayos de luna», y un CIPRÉS exclama con una bellísima metáfora que ya podemos considerar plenamente vanguardista:

¡Silencio!

Mi dedo verde

Sella la boca

Del crepúsculo.

Silencio.

Con este silencio acabamos también este recorrido.

\section{CONCLUSIONES}

El breve repaso de los primeros escritos juveniles teatrales de Lorca nos permite avanzar algunas conclusiones provisionales:

1) Lorca escribe estos textos bajo la influencia del simbolismo, el modernismo y el neorromanticismo.

2) Lorca poco a poco, sin embargo, logra superar los límites de estos movimientos estéticos.

3) Más allá de fuentes e influencias, estos textos muestran una originalidad, versatilidad, imaginación y experimentación que no podemos atribuir a influencias externas, sino que nacen de la propia personalidad creadora de García Lorca.

4) La concepción vital que Lorca tenía del arte le llevó a investigar e inventar formas y fórmulas nuevas, en las que el mundo de la plástica y la música tuvieron gran importancia y se integraron plenamente en la búsqueda de su propia voz literaria y poética.

5) Es dentro de este contexto personal donde vemos los primeros desbordamientos vanguardistas de la escritura de Lorca. 
6) La conexión y el contacto con los movimientos y el ambiente vanguardista de su época, afianzó en Lorca lo que podían ser tendencias internas poderosas, pero nunca le llevó a alejarse de un núcleo personal que no encajaba plenamente en los esquemas y aspiraciones de las vanguardias históricas.

7) No obstante, encontramos textos lorquianos plenamente vanguardistas, que sin duda constituyen parte de lo mejor que el vanguardismo generó en nuestro país, ocupando Lorca un lugar central en todo lo que se refiere a la presencia y vitalidad de las vanguardias históricas, no sólo a nivel nacional, sino internacional, como pueden demostrarlo títulos posteriores como El Público o Poeta en Nueva York.

8) No hemos de considerar estos textos del primer Lorca como un fruto aislado dentro de su producción. El estudio de estos textos juveniles teatrales nos muestra que cierta «actitud» vanguardista nació con su propia escritura, y que nunca renunció a experimentar e innovar en el terreno teatral y poético.

\section{REFERENCIAS BIBLIOGRÁFICAS}

ARAQUistáin, L. (1930). La batalla teatral. Madrid: Mundo Latino.

BALbOA, M. (1986). Lorca: El espacio de la representación. Reflexiones sobre surrealismo y teatro. Barcelona: Llibres del Mall.

CAO, A. (1978). Federico García Lorca y las vanguardias: Hacia el teatro. London: Támesis Books.

DíEz-CANedo, E. (1968). Panorama del teatro español de 1914 a 1936. Vol. 4: Elementos de renovación teatral. México: Joaquín Mortiz.

FRIGOLÉ, J. (1995). Un etnólogo en el teatro. Ensayo antropológico sobre Federico García Lorca. Barcelona: Mucknik.

GARCíA POSADA, M. (1989). «Lorca y el surrealismo: una relación conflictiva». Ínsula, 515: 7-9.

García LorCA, F. (1996). Obras completas. García Posada, M. ed. Barcelona: Círculo de Lectores.

García LorCA, F. (1980). Federico y su mundo Madrid: Alianza editorial.

GiBSon, J. (1998). Vida, pasión y muerte de Federico García Lorca. Barcelona: Plaza y Janés.

GóMEZ, A. (1996). Una teoría teatral de la ruptura: Lorca y la España de anteguerra. Málaga: Universidad de Málaga.

HARRETCHE, E. (1987). «Una cuestión debatida: el surrealismo de Lorca». Litoral, 174-176:199232.

HuÉLAMO, J. (1997). «Así que pasen cinco años: La memoria recuperada». En La mirada joven. Escritos sobre la literatura juvenil de Federico García Lorca, Soria, A. (ed.). Granada: Universidad de Granada.

- (1989). «La influencia de Freud en el teatro de Federico García Lorca». BFGL, 6: 59-83.

PAEPE, Ch. (1997). «Versos que no sean versos quiero hacer. La primera poética de F. García Lorca». En La mirada joven. Escritos sobre la literatura juvenil de Federico García Lorca, Soria, A. (ed.). Granada: Universidad de Granada.

SAlAZAR, J. (1999). «Rosas y mirtos de luna»... Naturaleza y símbolo en la obra de Federico García Lorca. Madrid: UNED.

Soria, A. (1994). Federico García Lorca, Teatro inédito de juventud. Madrid: Cátedra.

WAHNÓn, S. (1997). «Notas sobre el teatro juvenil de García Lorca: Ensayos de un Drama Dialógico». En La mirada joven. Escritos sobre la literatura juvenil de Federico García Lorca, Soria, A. (ed.). Granada: Universidad de Granada. 